\title{
Decision Support System (DSS) Determining Credit Customer Pada PT. Bank Rakyat Indonesia (Persero) Tbk
}

\author{
Muhamamd Fikry ${ }^{1}$, Nurmi, ${ }^{2}$ \\ ${ }^{1}$ Sistem Informasi, STMIK Indonesia Padang \\ ${ }^{2}$ Pendidikan Informatika, STKIP PGRI Padang \\ email: fiekrhie@yahoo.co.id \\ http://dx.doi.org/10.22202/jei.2014.v1i1.1437
}

\begin{abstract}
Computer as one advance sintechnology can help people to improve the quality and quantity of work, as well ashelp in getting the information and decision-making to decision making. The concept of decision support systems (decision support system) is one branch of artificial intelligence (artificial intelligence) that is widely used to help makea decision. Many methods can beapplied to decision support system to help providea solutioninaproblemalternaif. One such methodis a method ofdata cleaningand datatransformation. This method will help to process in complete data into acomplete data, then transform the data using theme thods of data transformation.
\end{abstract}

Keywords: decision support system, data cleaning, data transformasi, determining credit

\section{PENDAHULUAN}

Dunia usaha pada saat ini telah mengalami perkembangan teknologi informasi (TI) yang sangat pesat. Ini ditandai dengan munculnya perkembangan di berbagai dunia usaha. Perbankan salah satu dunia usaha yang mengalami perkembangan yang sangat pesat, tetapi lebih jauh dari itu dengan produkproduk baru yang menarik dan dikelola secara langsung maupun tidak langsung akan terjadi persaingan antara satu dengan yang lainnya.

Dengan kemajuan teknologi informasi tersebut, perangkat lunak (Softwere) juga mengalami perkembangan yang sangat pesat, seperti adanya sistem penunjang keputusan ( Decision Support System ) yang merupakan salah satu contoh pemrograman berbasis pengetahuan. Dengan adanya kemajuan teknologi informasi tersebut dari tahun ke tahun maka dunia perbankan juga mengalami kemajuan yang sangat pesat dari tahun ke tahun. Menurut Gorry dan Scoy Morton (1997) sistem penunjang keputusan adalah "interactive computer based systems, which help decision makers utilize data and model to solve unstructured problem". Sedangkan Keen dan Scot Morton (1998) memberikan defenisi yang lain yaitu "decision support systems couple the capabilities of the computer to improve the quality of decision. It is computer based support systems of management decision maker who deal with semi structured problem".

Sistem Penunjang Keputusan dirancang untuk mengembangkan efektifitas dan produktifitas dari para maneger dan kaum professional. sistem penunjang keputusan merupakan salah satu sistem yang dapat diimplementasikan dalam penyaluran kredit pada PT. Bank Rakyat Indonesia (Persero) Tbk. Bank Rakyat Indonesia adalah salah satu lembaga keuangan yang memberikan jasa tabungan, deposito berjangka dan pemberian fasilitas kredit kepada pengusaha kecil dan menengah. Dalam penyaluran pemberian kreditnya PT. Bank Rakyat Indonesia (Persero) Tbk belum mengaplikasikan suatu sistem yang berbasiskan komputer secara maksimal yang dapat menghasilkan berbagai alternatif keputusan untuk membantu manajemen dalam memutuskan pihak-pihak mana saja yang berhak diberikan kredit. Sistem ini yang akan dapat membantu perusahaan dalam mengalokasikan kredit sehingga optamalisasi kerja dapat senantiasa diharapkan.

Sistem pakar merupakan bagian Artificial Intelligent (kecerdasan buatan) yang mampu memodelkan proses penalaran ahli pada bidang tertentu, agar keahliannya / kepakarannya dapat dimanfaatkan oleh orang-orang non 
pakar karena tingkat keahlian dari program tersebut dapat menangani masalah, sebanding dengan kemampuan seorang ahli di bidang tersebut. Sistem pakar telah digunakan lingkup pemasalahan yang luas, penggunaan sistem pakar antara lain untuk: konsultasi, melakukan analisis dan diagnosis, membantu pengambilan keputusan, dan lain sebagainya. Umumnya sistem pakar dirancang untuk berinteraksi langsung dengan pemakai dalam format tertentu yang dapat memberikan keputusan sesuai penalaran.

\subsection{Tujuan Penelitian}

Tujuan dari penelitian ini adalah untuk menerapkan teknologi informasi dalam proses pengambilan keputusan pemberian kredit danmembantu pihak manajemen dalam pengambilan keputusan yang lebih cepat, tepat dan akurat.

\section{KAJIAN LITERATUR}

\subsection{Sistem Penunjang Keputusan}

Dalam tahun 1970, Scoot Morton menyampaikan konsep-konsep utama dari sistem penunjang keputusan. Dia mendefenisikan sistem penunjang keputusan sebagai :

"Komputer interaktif berbasiskan sistem yang mana dapat membantu dalam pengambilan keputusan dengan menggunakan data dan model untuk pemecahan masalah" (Gorry and Scoot Morton, 1971).

Defenisi lain dari sistem penunjang keputusan menurut Keen dan Scoot Morton (1978) adalah :

"Sistem Pengambilan Keputusan
menggunakan sumber daya individu yang
intelektual dengan kemampuan komputer
untuk meningkatkan mutu keputusan, Hal
ini merupakan Penggunaan komputer
berbasiskan sistem pendukungan bagi
manajemen pembuat keputusan yang
berhadapan dengan masalah setengah
tersusun."

Tiap- tiap bagian dari defenisi ini mempunyai sebuah konsep kunci yang menyumbangkan pada karakter yang unik dari sistem penunjang keputusan. Sistem penunjang keputusan adalah sistem berbasiskan komputer yang menambahkan teknologi didalamnya, sehingga dapat membantu dalam pengambilan keputusan.

\subsection{Komponen Sistem Penunjang \\ Keputusan}

Suatu sistem penunjang keputusan memiliki tiga subsistem utama yang menentukan kapabilitas teknis sistem penunjang keputusan tersebut, yaitu subsistem manajemen basis data, subsistem manajemen basis model, dan subsistem perangkat lunak penyelenggara dialog.

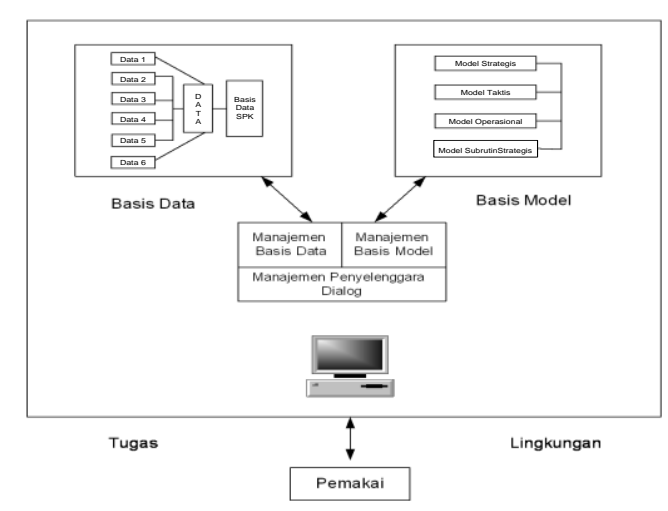

Gambar 1. Komponen Sistem Penunjang
Keputusan

\section{METODE PENELITIAN}

Dalam pendapatan data-data atau bahanbahan untuk penyusunan tugas ini digunakan beberapa metode penelitian.

\subsection{Field Research}

Mendapatkan data atau informasi dengan cara:

a) Interview

Metode ini dilakukan untuk memperoleh informasi atau data yang di inginkan dalam penulisan skripsi ini, yaitu dengan cara melakukan wawancara langsung dengan kepala bagian serta dengan pegawai yang ada.

\section{b) Questioner}

Yaitu membuat suatu daftar pertanyaan sehubungan dengan masalah yang diteliti. 


\subsection{LaboratoryResearch}

Penelitian yang dilakukan dilaboratorium komputer untuk melakukan pengolahan datadata yang telah dikumpulkan saat melakukan penelitian dan untuk mempraktekan langsung dari hasil analisa yang dilakukan. Penelitian yang dilakukan dilaboratorium ini menggunakan peralatan komputer dengan spesifikasisebagai berikut:

a. Komputer Intel® Core (TM) i5 2450M CPU@ 2.50Ghz

b. Storage Hardisk 360 GB.

c. Flash Disc 16 GB

d. Printer Canon IP 2770

e. Softwere pendukung yang digunakan dalam penyelesaian penelitian ini yaitu:
i. Sistem Operasi Widows 7
ii. Mocrosoft Office 2013
iii. Netbeans 8.0
iv. xampp-win32-1.8.3-2-VC11-installer

\subsection{Library Research}

Penelitian kepustakaan dilakukan dengan mencari dan mengumpulkan data-data serta dengan membaca buku-buku dan artikel yang berkaitan dengan penelitian ini.

\section{HASIL DAN PEMBAHASAN}

\section{analisis Sistem}

Analisa sistem yang merupakan langkah yang dapat dilakukan dengan mempelajari secara rinci bagaimana sistem yang ada beroperasi. Untuk mempelajari operasi dari sistem, maka diperlukan data yang dapat diperoleh dengan melakukan penelitian. Analisa sistem perlu dipelajari apa dan bagaimana operasi dari sistem yang ada sebelum mencoba untuk menganalisa permasalahan. Kelemahan-kelemahan dan kebutuhan pemakai sistem untuk memberikan rekomendasi pemecahannya. Hal ini dimaksudkan agar memudahkan kita untuk melakukan apa yang diinginkan sehingga sistem yang berjalan sebagaimana mestinya. Dengan kata lain sistem lama dapat dijadikan sebagai perbandingan untuk merancang sistem baru nantinya Jadi analisa sistem merupakan penguraian dari suatu sistem yang utuh kedalam bagian-bagian komponennya dengan maksud untuk mengidentifikasi dan mengevaluasi permasalahan serta hambatan- hambatan yang terjadi sehingga dapat diusulkan perbaikan.

\subsection{FaktorPertimbangan Kredit}

Faktor-faktor pertimbangan pemberian kredit pada PT. Bank Rakyat Indonesia pada dasarnya menggunakan prinsip 5C, namun pihak koperasi menggunakan faktor-faktor pertimbangan pemberian kredit yang lebih terinci, yaitu :

1. Kelayakan Usaha

Kelayakan usaha adalah penelitian tentang dapat tidaknya suatu usaha dilaksanakan dengan berhasil ada yang menafsirkan dalam artian yang lebih terbatas ada juga yang mengartikan dalam artian yang lebih luas.

2. Lingkungan kerja

Lingkungan kerja merupakan penelitian tentang kondisi lingkungan kerja disekitar tempat usaha calon nasabah didirikan.

3. Kondisi Ekonomi

Adalah keadaan sosial, ekonomi, status saat yang memungkinkan dapat memperngaruhi maju mundurnya usaha calon nasabah. Penilaian terhadap kondisi dimaksudkan untuk mengetahui sampai sejauh mana kondisi ekonomi itu berpengaruh terhadap kegiatan usaha calon nasabah dan bagaimana nasabah tersebut mengatasinya, sehingga usahanya tetap hidup dan berkembang.

4. Karakter Nasabah

Karakter nasabah adalah keadaan watak dan sifat dari calon nasabah baik dalam kehidupan pribadi maupun dalam lingkungan usahanya. Penilaian karakter nasabah merupakan penilaian terhadap kejujuran, ketulusan, kepatuhan akan janji, kesehatan, kecakapan dalam mengelola usaha serta kemauan untuk membayar kembali hutangnya.

5. Jaminan Nasabah

Menunjukan besar aktiva yang diserahkan calon nasabah sebagai jaminan atas kredit yang diterima.

\subsection{Metoda Data Cleaning}

Metoda data cleaning adalah suatu metoda yang digunakan untuk menangani data yang tidak lengkap, menghilangkan noise data dan data yang inkonsisten. Teknik yang digunakan 
pada metoda data cleaning adalah teknik mean substitution. Dalam teknik ini, data yang tidak lengkap diisi dengan nilai rata-rata dari sample data. Algoritma dari teknik mean substitution ini adalah sebagai berikut :

Algoritma 3.1: Teknik mean substitution Input : Data yang tidak lengkap

Output : Data lengkap

Method :

1. Hitung rata-rata dari sample data, $x=\frac{\Sigma \mathrm{Xi}_{1}}{n}$

2. Isi data tidak lengkap dengan nilai rata-rata

Pada waktu menginputkan nilai-nilai poin pada pertimbangan yang telah ditentukan oleh pihak Bank pada calon nasabah, maka dapat dilakukan dengan membuat nilai range dari nilai 0 sampai nilai 100. Pada sistem yang sedang berjalan terdapat lima penilaian pada calon nasabah, yaitu dapat kita lihat dengan ketentuan dibawah ini:

Table 1. Batas Nilai Pertimbangan

\begin{tabular}{|c|l|}
\hline Nilai & \multicolumn{1}{|c|}{ Keterangan } \\
\hline $80-100$ & Sangat Baik \\
$60-79$ & Baik \\
$40-59$ & Cukup Baik \\
$20-39$ & Kurang \\
$0-19$ & Kurang Sekali \\
\hline
\end{tabular}

Ilustrasi dari algorithma 3.1 dapat dilihat pada contoh-contoh berikut ini :

Tabel 2. Data Tidak Lengkap

\begin{tabular}{|l|c|c|c|c|c|c|}
\hline Calon Nasabah & $\begin{array}{c}\text { Jumlah } \\
\text { (Juta) }\end{array}$ & $\begin{array}{c}\text { Kelayakan } \\
\text { Usaha }\end{array}$ & $\begin{array}{c}\text { Lingkungan } \\
\text { Kerja }\end{array}$ & $\begin{array}{c}\text { Kondisi } \\
\text { Ekonomi }\end{array}$ & karakter & Jaminan \\
\hline Aburizal & 15 & 80 & 95 & 60 & 80 & 100 \\
\hline Sri Aminarti & 30 & 70 & 82 & 95 & 55 & 100 \\
\hline Edi Yanto & 50 & 90 & 60 & 70 & 72 & 85 \\
\hline Khairul Afkhar & 45 & $?$ & 80 & 40 & 70 & 80 \\
\hline Siti Khaira & 25 & 65 & 75 & $?$ & 65 & 90 \\
\hline Hasarudin & 10 & 45 & 85 & 75 & 90 & 95 \\
\hline Asman Anas & 35 & 90 & 65 & 70 & 85 & 100 \\
\hline Yulnis & 20 & 75 & 90 & 60 & 80 & 95 \\
\hline Mardison & 40 & 50 & 35 & 85 & $?$ & 80 \\
\hline Rosmayni & 55 & 73 & 75 & 90 & 75 & 90 \\
\hline
\end{tabular}

kelayakan usaha, lingkungan kerja dan kondisi

63.8, 64.5 dan 67.2 Berdasarkan nilai rata-rata ekonomi adalah :

Rata-rata $=$ jumlah keseluruhan data dari tersebut, tabel 2 yang berisi data tidak lengkap dapat menjadi data lengkap yang dapat dilihat sampel dibagi dengan banyak sample. pada tabel 3. Untuk mendapatkan data lengkap 
maka digunakan metode hitung rata- rata

dengan contoh sebagai berikut :

Tabel 3. Data Lengkap

\begin{tabular}{|l|c|c|c|c|c|c|}
\hline Calon Nasabah & $\begin{array}{c}\text { Jumlah } \\
\text { (Juta) }\end{array}$ & $\begin{array}{c}\text { Kelayakan } \\
\text { Usaha }\end{array}$ & $\begin{array}{c}\text { Lingkungan } \\
\text { Kerja }\end{array}$ & $\begin{array}{c}\text { Kondisi } \\
\text { Ekonomi }\end{array}$ & karakter & Jaminan \\
\hline Aburizal & 15 & 80 & 95 & 60 & 80 & 100 \\
\hline Sri Aminarti & 30 & 70 & 82 & 95 & 55 & 100 \\
\hline Edi Yanto & 50 & 90 & 60 & 70 & 72 & 85 \\
\hline Khairul Afkhar & 45 & 63.8 & 80 & 40 & 70 & 80 \\
\hline Siti Khaira & 25 & 65 & 75 & $\underline{64.5}$ & 65 & 90 \\
\hline Hasarudin & 10 & 45 & 85 & 75 & 90 & 95 \\
\hline Asman Anas & 35 & 90 & 65 & 70 & 85 & 100 \\
\hline Yulnis & 20 & 75 & 90 & 60 & 80 & 95 \\
\hline Mardison & 40 & 50 & 35 & 85 & $\underline{67.2}$ & 80 \\
\hline Rosmayni & 55 & 73 & 75 & 90 & 75 & 90 \\
\hline
\end{tabular}

\subsection{Data Tranformasi}

Data transformasi adalah suatu metoda yang digunakan untuk mentransformasikan basis data kedalam data yang ditransformasikan yaitu dengan melakukan normalisasi dan pengumpulan data sehinggga menjadi sama. Algoritma dari data transformasi adalah sebagai beriikut: Algoritma 3.2 : Data Transformasi Input : Data lengkap Output :Data yang ditranformasikan Method :

1. Tentukan nilai terbesar $(\mathrm{Xmax})$,dan nilai terkecil (Xmin)

2. Tentukan range nilai $(\mathrm{Xrange}=\mathrm{X} \max -$ Xmin)

3. Tentukan jumlah kelas, $\mathrm{K}=1+3,3 \log$ (n).

$$
\mathrm{n}=\text { banyak sampel }
$$

4. Tentukan nilai interval, Int $=$ Xrange $/ \mathrm{K}$.

5. Tranformasikan data dengan $\{X \min ,[$ $\mathrm{Xmin}+\mathrm{Int}]\}$.

Ilustrasi dari algoritma 3.2 diberikan pada contoh berikut ini :

Dengan menggunakan data lengkap pada tabel 3 maka dapat dilihat nilai terkecil untuk masing - masing atribut.

1. Atribut kelayakan usaha a. nilai terbesarnya adalah 90 dan nilai terkecilnya 45.

b. range nilai adalah $90-45=45$.

c. jumlah kelas adalah $1+3,3 \log (10)=4$

d. nilai interval adalah $45 / 4=11$
Tranformasi yang dihasilkan

Nilai terkecil dari sampel + Nilai interval $=$ Data tranformasi

$$
\begin{aligned}
& 45-56=1 \\
& 57-68=2 \\
& 69-80=3 \\
& 81-92=4
\end{aligned}
$$

2. Atribut lingkungan kerja

a. nilai terbesarnya adalah 95 dan nilai terkecilnya 35 .

b. range nilai adalah $95-35=60$.

c. jumlah kelas adalah $1+3,3 \log (10)=4$

d. nilai interval adalah

$$
60 / 4=15
$$

Tranformasi yang dihasilkan

Nilai terkecil dari sampel + Nilai interval $=$ Data tranformasi

$$
\begin{aligned}
& 35-50=1 \\
& 51-66=2 \\
& 67-82=3 \\
& 83-98=4
\end{aligned}
$$

3. Atribut kondisi ekonomi
a. nilai terbesarnya adalah
95 dan nilai terkecilnya 40.
b. range nilai adalah $95-40=55$.
c. jumlah kelas adalah $1+3,3 \log (10)=4$
d. nilai interval adalah

$$
55 / 4=14
$$

Tranformasi yang dihasilkan

Nilai terkecil dari sampel + Nilai interval $=$ Data tranformasi 


\section{Jurnal Edik Informatika}

$$
\begin{aligned}
& 40-54=1 \\
& 55-69=2 \\
& 70-84=3 \\
& 85-99=4
\end{aligned}
$$

4. Atribut karakter

a. nilai terbesarnya adalah

90 dan nilai terkecilnya 55.

b. range nilai adalah

$$
90-55=35 \text {. }
$$

c. jumlah kelas adalah

$$
1+3,3 \log (10)=4
$$

d. nilai interval adalah

$$
35 / 4=9
$$

Tranformasi yang dihasilkan

Nilai terkecil dari sampel + Nilai interval

$=$ Data tranformasi

$$
\begin{aligned}
& 55-64=1 \\
& 65-74=2 \\
& 75-84=3 \\
& 85-94=4
\end{aligned}
$$

5. Atribut Jaminan

a. nilai terbesarnya adalah 100 dan nilai terkecilnya 80 .

b. range nilai adalah $100-80=20$.

c. jumlah kelas adalah $1+3,3 \log (10)=4$

d. nilai interval adalah

$$
20 / 4=5
$$

Tranformasi yang dihasilkan

Nilai terkecil dari sampel + Nilai interval $=$ Data tranformasi

$$
\begin{aligned}
& 80-85=1 \\
& 86-91=2 \\
& 92-97=3 \\
& 98-103=4
\end{aligned}
$$

Berdasarkan nilai diatas, data lengkap dari tabel 3 dapat ditransformasikan kedalam tabel 4.

Tabel 4. Data Transformasi

\begin{tabular}{|l|c|c|c|c|c|}
\hline Calon Nasabah & $\begin{array}{c}\text { Kelayakan } \\
\text { Usaha }\end{array}$ & $\begin{array}{c}\text { Lingkungan } \\
\text { Kerja }\end{array}$ & $\begin{array}{c}\text { Kondisi } \\
\text { Ekonomi }\end{array}$ & karakter & Jaminan \\
\hline Aburizal & 4 & 2 & 3 & 4 & 3 \\
\hline Sri Aminarti & 3 & 4 & 1 & 4 & 3 \\
\hline Edi Yanto & 2 & 3 & 2 & 1 & 4 \\
\hline Khairul Afkhar & 3 & 1 & 2 & 1 & 2 \\
\hline Siti Khaira & 3 & 2 & 2 & 2 & 2 \\
\hline Hasarudin & 4 & 3 & 4 & 3 & 1 \\
\hline Asman Anas & 2 & 3 & 4 & 4 & 4 \\
\hline Yulnis & 4 & 2 & 3 & 3 & 3 \\
\hline Mardison & 1 & 4 & $\underline{2}$ & 1 & 1 \\
\hline Rosmayni & 3 & 4 & 3 & 2 & 3 \\
\hline
\end{tabular}

\subsection{Penentuan Keputusan}

Penentuan keputusan dengan komputerisasi merupakan hasil dari pemrosesan program agar keputusan yang dihasilkan tepat, cepat, dan akurat. Pada pengentrian data tidak lengkap komputer memproses data dan menghasilkan keputusan apakah keputusan kredit tersebut ditolak, dipertimbangkan, atau diterima. Keputusan kredit dengan komputerisasi dihasilkan dengan ketentuan sebagai berikut :

1. $\quad$ Nilai $\operatorname{Min}=1$ (nilai data yang dihasilkan dari data transformasi Min)

2. Jumlah $\operatorname{Max}=4$ (nilai data yang dihasilkan dari data transformasi Max)

3. Median $=$ Jumlah Max : Jumlah Min $=4: 1$
$=2,5$ (Dibulatkan)

$=2$

4. Jumlah Keputusan $=2$

- Diterima

- Ditolak

5. Jumlah interval keputusan

$=$ jumlah atribut $\mathrm{X}$ Median

$=5 \times 2$

$=10$

Jumlah interval keputusan ini digunakan sebagai standarisasi dalam pengklasifikasian nilai tiap - tiap calon nasabah.

\subsection{Manajeman Basis Model}

Model merupakan metode yang digunakan untuk membuat keputusan, walaupun keputusan telah dihasilkan oleh komputerisasi berdasarkan laporan data tranformasi namun keputusan kredit tersebut harus 
dipertimbangkan kembali berdasarkan kelebihan poin dari atribut dimana apabila terdapat atribut yang tidak memenuhi standar, maka dapat ditutupi oleh atribut lainya jika atribut tersebut memiliki poin yang lebih besar dari standarisasi yang telah ditentukan dalam penerimaan kredit ,misal :

a. Pada atribut kelayakan usaha standar poin adalah 50 sedangkan calon nasabah memiliki poin 75

b. Pada atribut lingkungan kerja standar poin adalah 30 sedangkan calon nasabah hanya memiliki poin 15

Jadi, kekurangan poin pada atribut lingkungan kerja dapat tertutupi oleh kelebihan poin pada atribut kelayakan usaha yang memungkinkan keputusan pemberian kredit dapat dipertimbangkan kembali.

Untuk mempresentasikan pemberian alternatif terbaik dari alternatif yang ada, penulis menggunakan model dengan aturan berbentuk : IF - THEN.

$$
\begin{aligned}
& \text { IF jumlah }>=10 \text { THEN } \\
& \text { keterangan }=\text { diterima }
\end{aligned}
$$$$
\text { ELSE }
$$

IF jumlah $<10$ THEN

$$
\text { keterangan }=\text { ditolak }
$$

ket:

jumlah merupakan total dari standarisasi Kelayakan Usaha, Lingkungan Kerja, Kondisi Ekonomi, Karakter Nasabah serta Jaminan yang terdapat pada data Transformasi.

Standarisasi untuk setiap faktor pertimbangan diambil dari nilai Median antara data transformasi Maksimal dengan data transformasi Minimal dari data Transformasi. Pada contoh kasus diatas maka dapat diambil nilai Median (nilai standar) yaitu 2 untuk setiap faktor pertimbangan, sehingga dari 5 faktor didapatkan nilai jumlah (total standarisasi) yaitu 10. Namun nilai tersebut dapat berubah sesuai dengan range nilai dan jumlah data.

Dari aturan yang telah ditetapkan sebelumnya, maka dapat diketahui calon nasabah yang layak untuk menerima kredit. Daftar nama calon nasabah yang diterima atau ditolak saat pemberian kredit dapat dilihat pada tabel 5 .

Tabel 5 Tabel Keputusan

\begin{tabular}{|c|c|c|c|c|c|c|c|}
\hline Calon Nasabah & $\begin{array}{c}\text { Kelayaka } \\
\text { n Usaha }\end{array}$ & $\begin{array}{c}\text { Lingkungan } \\
\text { Kerja }\end{array}$ & $\begin{array}{c}\text { Kondisi } \\
\text { Ekonomi }\end{array}$ & karakter & Jaminan & Jumlah & Keputusan \\
\hline Aburizal & 3 & 4 & 2 & 3 & 4 & $\mathbf{1 6}$ & Diterima \\
\hline Sri Aminartid & 3 & 3 & 4 & 1 & 4 & $\mathbf{1 5}$ & Diterima \\
\hline Edi Yanto & 4 & 2 & 3 & 2 & 1 & $\mathbf{1 2}$ & Diterima \\
\hline $\begin{array}{c}\text { Khairul } \\
\text { Afkhar }\end{array}$ & $\underline{2}$ & 3 & 1 & 2 & 1 & $\mathbf{9}$ & Ditolak \\
\hline Siti Khaira & 2 & 3 & $\underline{2}$ & 2 & 2 & $\mathbf{1 1}$ & Diterima \\
\hline Hasarudin & 1 & 4 & 3 & 4 & 3 & $\mathbf{1 5}$ & Diterima \\
\hline Asman Anas & 4 & 2 & 3 & 4 & 4 & $\mathbf{1 7}$ & Diterima \\
\hline Yulnis & 3 & 4 & 2 & 3 & 3 & $\mathbf{1 5}$ & Diterima \\
\hline Mardison & 1 & 1 & 4 & $\underline{2}$ & 1 & $\mathbf{9}$ & Ditolak \\
\hline Rosmayni & 3 & 3 & 4 & 3 & 2 & $\mathbf{1 5}$ & Diterima \\
\hline
\end{tabular}

\section{KESIMPULAN}

1. Dari hasil perancangan sistem teknologi informasi dapat diperoleh hasil yang lebih baik dari sebelumnya, dimana pengambilan keputusan dalam pemberian kredit dapat dilakukan secara efesien. Disamping ini juga dapat menghasilkan informasi dalam pemberian kredit lebih cepat dari sebelumnya.
2. Dengan menggunakan sistem teknologi informasi sebagai hasil dari rancangan yang baru, dapat meningkatkan mutu dan kualitas layanan kepada nasabah atau calon nasabah pada PT. Bank Rakyat Indonesia.

3. Perancangan sistem yang baru ini bertujuan untuk menghasilkan informasi yang cepat, tepat, dan akurat. Namun hasil 
keputusan yang dihasilkan dari pengolahan komputerisasi ini tetap akan dipertimbangkan lagi oleh pimpinan.

\section{PUSTAKA}

\section{Bahan Sosialisasi PT.Bank Rakyat Indonesia (Persero),Pedoman Pelaksanaan Krdit (PKK) Credit Risk Rating Dan Klasifikasi Warna Putusan Delegasi Wewenang Kredit: Kantor Pusat BRI Jakarta, 2001.}

Fikri, Rijalul, dkk,Pemrograman Java. Yogyakarta: Andi, 2005.

Kadarsah, Suryadi dan M. Ali Ramdhani.. Sistem Pendukung

Keputusan.Bandung: PT Remaja Rosda Karya, 2000

Kusrini, M. Kom.. Konsep dan Aplikasi Sistem Pendukung Keputusan. STMIK AMIKOM Yogyakarta: Andi., 2007

Modul pendidikan untuk Deskman dan Teller. Kredit Umum Pedesaan: Kantor Pusat BRI Jakarta, 2004.

Sanjaya, Ridwan. Pengolahan Database MySQL 5 dengan Java 2 disertai Teknik Pencetakan Laporan. Yogyakarta: Andi, 2005 